NASA/TM-2010-216350

\title{
Coupled Analysis of an Inlet and Fan for a Quiet Supersonic Jet
}

Rodrick V. Chima

Glenn Research Center, Cleveland, Ohio

Timothy R. Conners and Thomas R. Wayman

Gulfstream Aerospace Corporation, Savannah, Georgia 


\section{NASA STI Program . . . in Profile}

Since its founding, NASA has been dedicated to the advancement of aeronautics and space science. The NASA Scientific and Technical Information (STI) program plays a key part in helping NASA maintain this important role.

The NASA STI Program operates under the auspices of the Agency Chief Information Officer. It collects, organizes, provides for archiving, and disseminates NASA's STI. The NASA STI program provides access to the NASA Aeronautics and Space Database and its public interface, the NASA Technical Reports Server, thus providing one of the largest collections of aeronautical and space science STI in the world. Results are published in both non-NASA channels and by NASA in the NASA STI Report Series, which includes the following report types:

- TECHNICAL PUBLICATION. Reports of completed research or a major significant phase of research that present the results of NASA programs and include extensive data or theoretical analysis. Includes compilations of significant scientific and technical data and information deemed to be of continuing reference value. NASA counterpart of peer-reviewed formal professional papers but has less stringent limitations on manuscript length and extent of graphic presentations.

- TECHNICAL MEMORANDUM. Scientific and technical findings that are preliminary or of specialized interest, e.g., quick release reports, working papers, and bibliographies that contain minimal annotation. Does not contain extensive analysis.

- CONTRACTOR REPORT. Scientific and technical findings by NASA-sponsored contractors and grantees.
- CONFERENCE PUBLICATION. Collected papers from scientific and technical conferences, symposia, seminars, or other meetings sponsored or cosponsored by NASA.

- SPECIAL PUBLICATION. Scientific, technical, or historical information from NASA programs, projects, and missions, often concerned with subjects having substantial public interest.

- TECHNICAL TRANSLATION. Englishlanguage translations of foreign scientific and technical material pertinent to NASA's mission.

Specialized services also include creating custom thesauri, building customized databases, organizing and publishing research results.

For more information about the NASA STI program, see the following:

- Access the NASA STI program home page at http://www.sti.nasa.gov

- E-mail your question via the Internet to help@ sti.nasa.gov

- Fax your question to the NASA STI Help Desk at 443-757-5803

- Telephone the NASA STI Help Desk at 443-757-5802

- Write to: NASA Center for AeroSpace Information (CASI) 7115 Standard Drive Hanover, MD 21076-1320 
NASA/TM-2010-216350

\section{Coupled Analysis of an Inlet and Fan for a Quiet Supersonic Jet}

\section{Rodrick V. Chima}

Glenn Research Center, Cleveland, Ohio

Timothy R. Conners and Thomas R. Wayman

Gulfstream Aerospace Corporation, Savannah, Georgia

Prepared for the

48th Aerospace Sciences Meeting

sponsored by the American Institute of Aeronautics and Astronautics Orlando, Florida, January 4-7, 2010

National Aeronautics and

Space Administration

Glenn Research Center

Cleveland, Ohio 44135 


\section{Acknowledgments}

The authors would like to thank Dr. Daniel L. Tweedt of AP Solutions, Inc. for the development and support of the SIGG, AVCS, SYNCEX, and SMPI codes, and John R. Whurr of Rolls-Royce plc for providing the geometry and operating conditions for the Tay fan.

Trade names and trademarks are used in this report for identification only. Their usage does not constitute an official endorsement, either expressed or implied, by the National Aeronautics and Space Administration.

This work was sponsored by the Fundamental Aeronautics Program at the NASA Glenn Research Center.

Level of Review: This material has been technically reviewed by technical management.

Available from

NASA Center for Aerospace Information 7115 Standard Drive

Hanover, MD 21076-1320
National Technical Information Service 5301 Shawnee Road Alexandria, VA 22312 


\title{
Coupled Analysis of an Inlet and Fan for a Quiet Supersonic Jet
}

\author{
Rodrick V. Chima \\ National Aeronautics and Space Administration \\ Glenn Research Center \\ Cleveland, Ohio 44135 \\ Timothy R. Conners and Thomas R. Wayman \\ Gulfstream Aerospace Corporation \\ Savannah, Georgia 31402
}

\begin{abstract}
A computational analysis of a Gulfstream isentropic external compression supersonic inlet coupled to a Rolls-Royce fan has been completed. The inlet was designed for a small, low sonic boom supersonic vehicle with a design cruise condition of $M=1.6$ at 45,000 feet. The inlet design included an annular bypass duct that routed flow subsonically around an engine-mounted gearbox and diverted flow with high shock losses away from the fan tip. Two Reynolds-averaged Navier-Stokes codes were used for the analysis: an axisymmetric code called AVCS for the inlet and a 3-D code called SWIFT for the fan. The codes were coupled at a mixing plane boundary using a separate code for data exchange. The codes were used to determine the performance of the inlet / fan system at the design point and to predict the performance and operability of the system over the flight profile. At the design point the core inlet had a recovery of 96 percent, and the fan operated near its peak efficiency and pressure ratio. A large hub radial distortion generated in the inlet was not eliminated by the fan and could pose a challenge for subsequent booster stages. The system operated stably at all points along the flight profile. Reduced stall margin was seen at low altitude and Mach number where flow separated on the interior lips of the cowl and bypass ducts. The coupled analysis gave consistent solutions at all points on the flight profile that would be difficult or impossible to predict by analysis of isolated components.
\end{abstract}

\section{Introduction}

In Practical Intake Aerodynamic Design", editor J. Seddon wrote, "One of the more fundamental problems in intake design is matching the intake and engine flow rates at off-design conditions." However, inlets are generally designed by the airframe manufacturer, engines are designed by the engine manufacturer, and the two are not closely integrated until well into the design process.

Inlets are regularly modeled using computational fluid dynamics (CFD) and tested in sub-scale wind tunnel tests. Distortion patterns are measured at an aerodynamic interface plane (AIP) using SAE 1420 standards $^{2}$ and supplied to the engine company. The engine company may model the effects of distortion on the fan using a parallel compressor model or higher order CFD models, or test an isolated fan or the entire engine using screens to simulate the inlet distortion.

CFD modeling also tends to be segregated by component, although a few researchers have attempted to model coupled inlet / fan systems. Hsiao, et al. ${ }^{3}$ modeled a subsonic nacelle with a Reynolds-averaged Navier-Stokes (RANS) CFD code and modeled the fan stage using an actuator duct model. They showed that the fan could increase the nacelle separation angle of attack by 3-4 degrees. Davis, et al. ${ }^{4}$ described an Integrated Test and Evaluation approach used at AEDC to support both test and analysis of integrated inlet/engine systems. In that work they modeled the forebody, inlet, and fan of the Joint Strike Fighter F-35 aircraft and predicted the effects of inlet distortion on the fan map. Chima, et al. ${ }^{5}$ coupled two CFD codes and used them to model an experimental test rig consisting of a serpentine inlet, fan stage, and nozzle. That work showed the effects of inlet distortion on the fan pressure ratio and examined distortion transfer through the fan.

In Ref. 6 retired inlet-engine integration engineer W. G. Steenken wrote that if the compression system team provides as high a stability limit as possible and the inlet / cycle team provides as low an operating line as possible then the desired stability margins can be achieved across the complete altitude-Mach number flight envelope. The present work used coupled CFD codes to model some of the tasks of these two teams and to predict the operating line and stability line of an inlet / fan system. 
Here two CFD codes were coupled and used to model the inlet and fan of a Quiet Supersonic Jet (QSJ) being studied by engineers at Gulfstream Aerospace Corporation (GAC). The work had four main objectives: 1. Development of CFD tools for the analysis of inlet / fan interaction. 2. Application of those tools to the propulsion system of the QSJ. 3. Determination of the inlet / fan system performance at the design point. 4. Assessment of the performance and operability of the system over the flight profile. The QSJ is described in section II below, and then each of the four objectives and how they were accomplished are described in sections III - VI. Finally, a summary of the work and conclusions are given in section VII.

\section{Quiet Supersonic Jet (QSJ)}

Engineers at GAC are investigating technologies that would enable the use of a small aircraft capable of quiet, environmentally acceptable, supersonic flight over land. The QSJ study aircraft shown in Figure 1 was designed to cruise at a Mach number of 1.6 at 45,000 feet. The aircraft would use radical aerodynamic shaping and a Quiet Spike $^{7}$ to minimize sonic boom. It is apparent that the inlets make up a large fraction of the frontal area of the aircraft, so they must be designed carefully to minimize their contribution to the overall sonic boom characteristics of the vehicle.

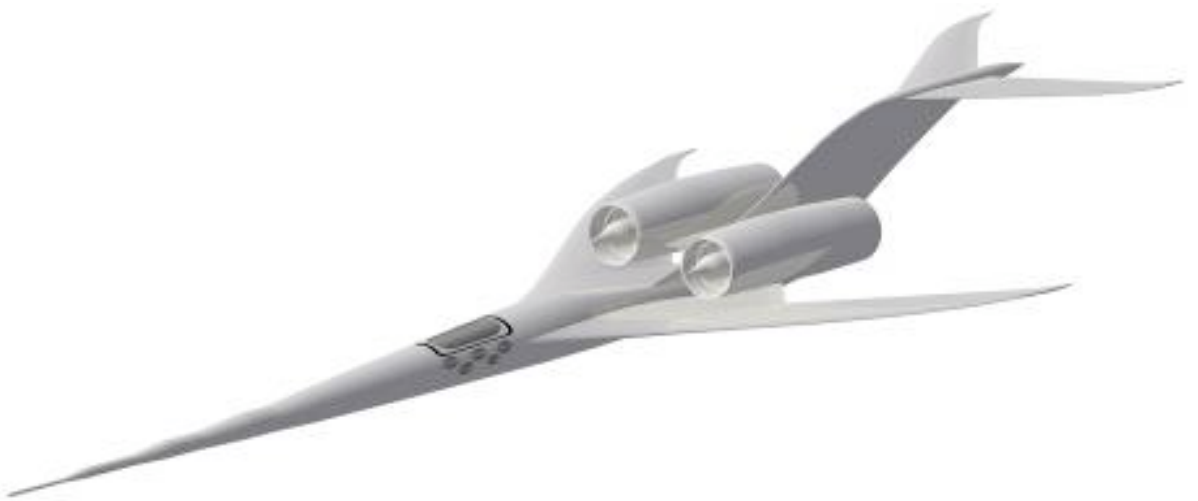

Figure 1. Gulfstream QSJ study aircraft.

The propulsion system, shown in Figure 2, consists of fixed-geometry external compression inlets, Rolls-Royce Tay engines, and fixed-geometry plug nozzles. The Tay engines are in the 15,000 lb takeoff thrust class and have a bypass ratio of 3.1 .

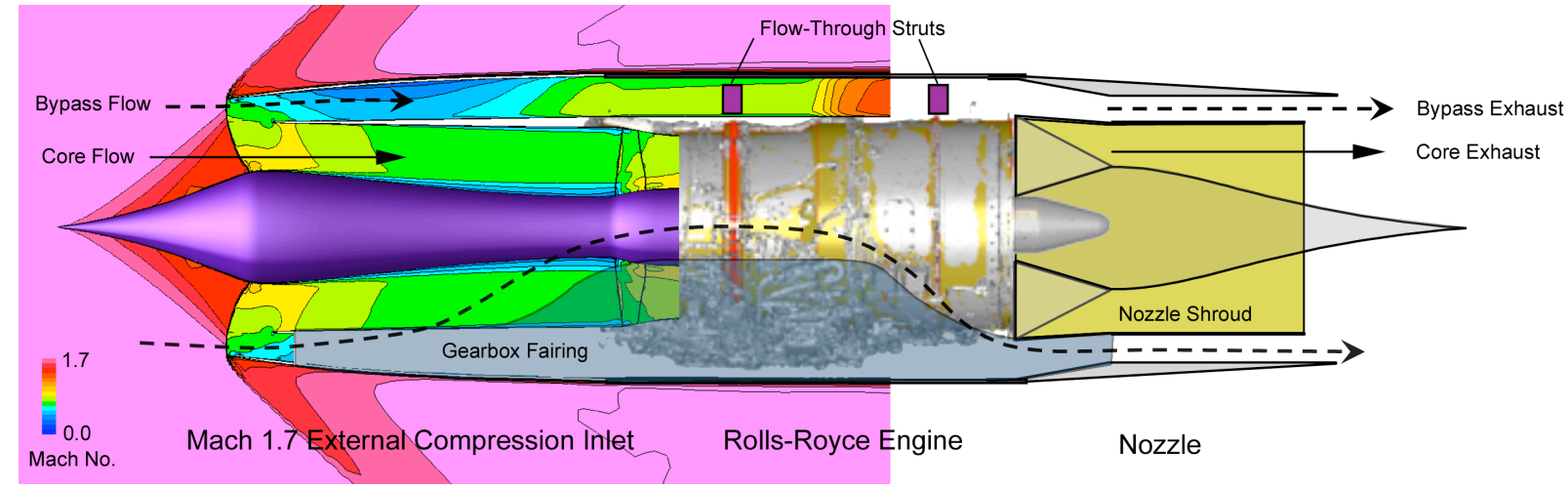

Figure 2. Gulfstream Mach 1.7 external compression inlet, Rolls-Royce Tay engine, and plug nozzle.

The external-compression inlets are of critical importance for this aircraft. They must reduce the Mach number from 1.7 over the wing to about 0.65 at the fan face, with high total pressure recovery, minimal distortion, and with minimal sonic boom. Conners and Howe at GAC have developed a novel approach for designing the external compression surface of the inlet that gives improved recovery and reduced sonic boom overpressures over conventional designs ${ }^{8}$. Inlets designed with this approach have been tested experimentally ${ }^{9}$ and modeled computationally $^{10,11}$, and shown to have good recovery and stability characteristics. 
The inlet considered here consists of an isentropic compression spike, a rounded throat region, and a subsonic diffuser. The compression spike was designed to produce a variable-strength normal shock at the throat. The Mach number ahead of the shock is about 1.3 on the centerbody, which is low enough to avoid boundary layer separation. The Mach number at the cowl is close to the design over-wing value of 1.7, which generates a strong normal shock and considerable shock loss.

Like many other engines the Tay has a large gearbox on the bottom. On a conventional subsonic aircraft the gearbox would be contained within a thick nacelle or an external pod. On a supersonic aircraft the nacelle thickness must be minimized and a large external pod must be avoided to minimize external shock waves. Instead, the inlet shown in Figure 2 has a novel bypass duct between the engine and the nacelle that channels the flow subsonically around a gearbox fairing, expands it back to supersonic in converging-diverging passages, and exhausts it around the engine flow in the nozzle. The bypass design has the additional advantage of diverting the low total pressure flow from the cowl shock through the bypass while providing clean flow to the fan tip.

\section{CFD Tools}

The first objective of the present work was to develop CFD tools for the analysis of inlet/fan interaction. This section describes two CFD codes used for the fan and inlet, and two codes used to couple them together.

\section{A. SWIFT}

SWIFT was used to analyze the flow in the Tay fan, both as an isolated fan and coupled to the Gulfstream inlet. It is a multi-block RANS code developed by R. Chima for analysis of turbomachinery blade rows ${ }^{12}$. The code solves the Navier-Stokes equations on body-fitted grids using an explicit finite-difference scheme. Inviscid fluxes are discretized using the advective upwind splitting method $\left(\mathrm{AUSM}^{+}\right)^{13}$. Viscous terms are included in the blade-toblade and hub-to-tip directions, but neglected in the streamwise direction using the thin-layer approximation. The discretized equations are solved with a multistage Runge-Kutta scheme using a spatially varying time step and implicit residual smoothing to accelerate convergence. Turbulent flows are modeled using the Wilcox $k-\omega$ turbulence model ${ }^{14}$. The numerical implementation of the model was described for a two-dimensional case in Ref. 15. Calculations for the isolated fan took about 4 hours per case on a personal computer (PC) with 2 Intel Xeon CPUs operating at $3.8 \mathrm{GHz}$.

\section{B. Axisymmetric Viscous CFD Solver (AVCS)}

AVCS is a RANS code developed by D. Tweedt and R. Chima for analysis of axisymmetric flows in ducts ${ }^{16}$. Here it was used to analyze the Gulfstream inlet, bypass duct, and external flow field. The code solves the axisymmetric Navier-Stokes equations and includes blockage terms that were used here to model the effects of the gearbox and struts in the bypass duct. Like SWIFT, AVCS uses the AUSM ${ }^{+}$upwind differencing scheme ${ }^{13}$ and the $\mathrm{k}-\omega$ turbulence model $^{14,15}$.

\section{Synchronized Data Exchange Code (SYNCEX)}

SYNCEX is a small code written in the C programming language by D. Tweedt. SYNCEX runs in the background and handles data transfer, storage, and synchronization between grids in AVCS using the following procedure:

1. Separate copies of AVCS are run for each grid. After each iteration each copy of AVCS passes interior solution data at grid interfaces to SYNCEX. The calling routine pauses.

2. SYNCEX buffers the data internally until it has received data from both sides of the interface.

3. SYNCEX transfers the data to the neighboring grid and returns control to the calling routine, thus ensuring synchronization between the solutions.

\section{SYNCEX Mixing Plane Interface (SMPI)}

SMPI is a Fortran code also written by D. Tweedt. It is used to couple the axisymmetric AVCS calculations with the 3-D SWIFT calculations. SMPI runs in the background and applies mixed-out boundary conditions at the AIP between the inlet and fan grids using the following procedure:

1. After each iteration AVCS and SWIFT pass their interior solutions to SMPI using calls to SYNCEX.

2. SMPI averages the SWIFT solution circumferentially using a mixed-out average to ensure conservation.

3. SMPI interpolates the averaged SWIFT solution to the radial location of its neighbor and transfers that solution to AVCS.

4. AVCS updates its boundary points and continues. 
5. SMPI uses two-dimensional steady characteristic boundary conditions developed by Giles ${ }^{17}$ to calculate boundary values for SWIFT. The boundary conditions are written as perturbations about the axisymmetric solution from AVCS that allow the SWIFT solution to vary tangentially along the boundary. The boundary values are transferred to SWIFT.

6. SWIFT updates its boundary points and continues.

\section{Application to the QSJ Propulsion System}

The second objective of the present work was to apply the CFD tools to the propulsion system of the Quiet Supersonic Jet. This involved generating matched grids for the inlet and fan, development of a blockage schedule for the bypass duct, and running the codes for both isolated components and the coupled inlet / fan system.

\section{A. Inlet and Bypass Grids}

Computational grids for the inlet, bypass, and external flow were generated using the SIGG code developed by D. Tweedt. The axisymmetric grid for the inlet and a meridional view of the fan grid are shown in Figure 3 where every third point is shown. The grid had three blocks for the core, bypass, and external flow. The spacing at the walls was $5 \times 10^{-4}$ inches, giving $y^{+}=2$ to 4 at the first point off the walls. Sizes for the individual blocks are given in Table 1. The overall grid had about 110,000 points.

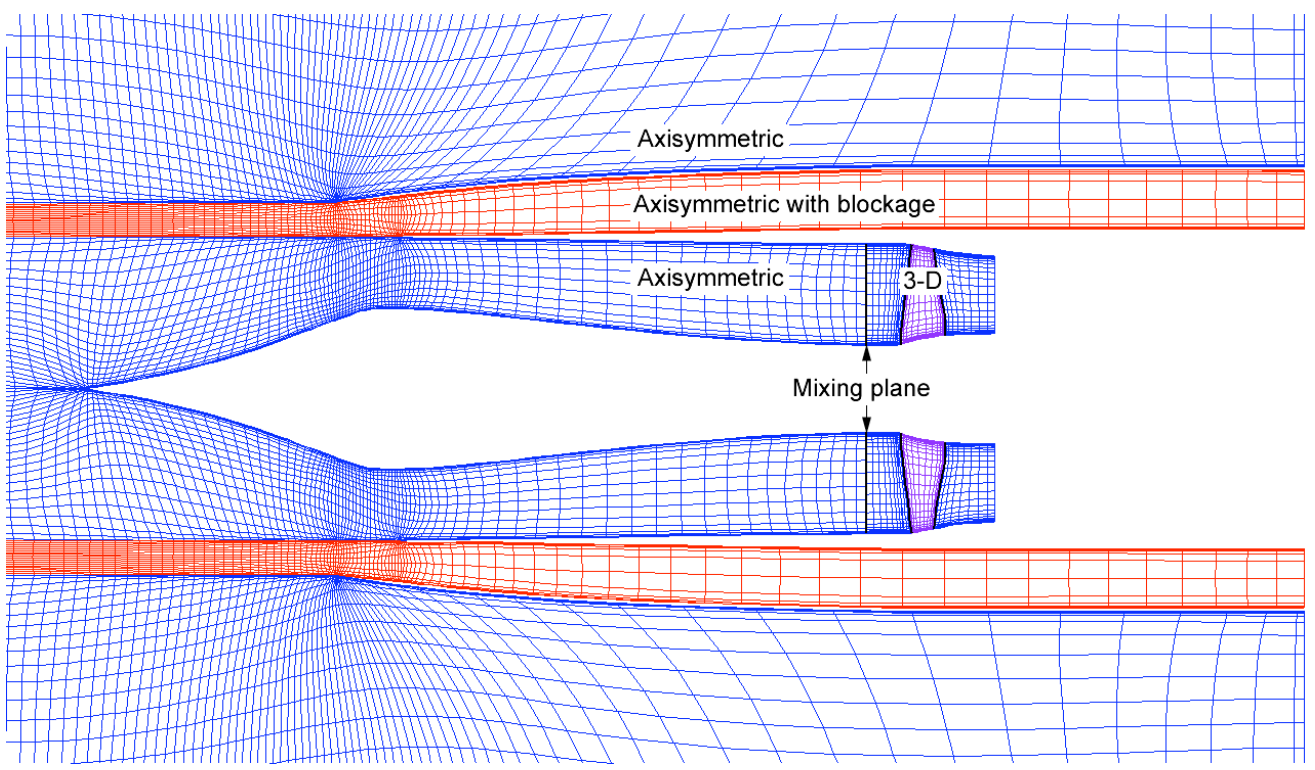

Figure 3. Computational grids for the inlet, bypass, external flow, and fan rotor.

\begin{tabular}{|l|c|c|c|}
\hline Region & Type & Size (x, r) & Total points \\
\hline inlet & $\mathrm{H}$ & $419 \times \quad 95$ & 39,805 \\
\hline bypass & $\mathrm{H}$ & $439 \times 55$ & 24,145 \\
\hline external flow & $\mathrm{H}$ & $360 \times 128$ & 46,080 \\
\hline Total & & & 110,030 \\
\hline
\end{tabular}

Table 1. Grid sizes for the inlet, bypass duct, and external flow.

\section{B. Bypass Blockage Model}

The gearbox is contained within a fairing that fills about 160 degrees circumference of the bypass duct at its maximum extent. Nine thin, curved struts divide the remainder of the annulus into 10 roughly parallel channels that carry the flow around the gearbox. The struts are shaped to form converging-diverging (C-D) sections towards the rear of the engine to re-expand the flow to supersonic at the nozzle. The passages choke at the start of the C-D sections and the present calculations were stopped just downstream of the choke plane.

The AVCS code includes an axisymmetric blockage term that was used to model the tangential blockage of the gearbox fairing and struts. The area distribution was taken from the design geometry and specified at each grid point in the bypass duct as shown in Figure 4. 


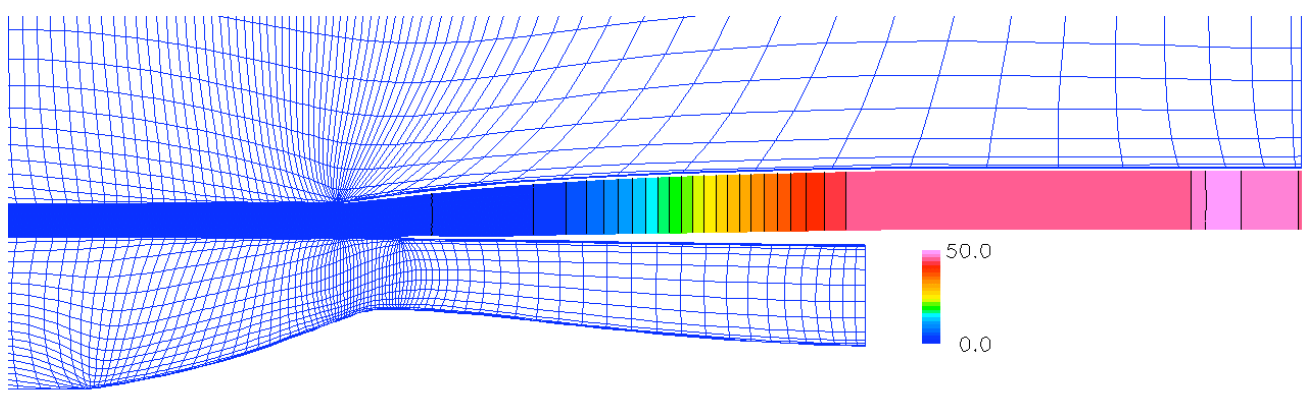

Figure 4. Percent blockage in the bypass duct due to the engine gearbox.

\section{Fan Grid}

The geometry for the Tay fan rotor was provided by Rolls-Royce. The Tay engine has a bypass splitter behind the rotor with a bypass ratio of 3.1, but in this study the rotor was treated as an isolated fan with the actual duct contours downstream.

The computational grid for the fan was generated using the TCGRID code developed by R. Chima. A 3-D view of the grid is shown in Figure 5. The fan grid had three blocks as shown in Figure 6 where every third point is shown. An H-grid was used ahead of the blades to allow the shocks to propagate into the inlet. The interface between the inlet and fan grids was placed at the AIP. A C-grid was used around the blades with a wall spacing of $3 \times 10^{-4}$ inches, giving $y^{+}=1.5$ to 2.5 at the first grid point off the walls. An O-grid shown in Figure 7 was used in the tip clearance, which was estimated to be 0.025 inches high. Grid sizes are given in Table 2. The overall grid for the fan rotor had about 1.3 million points.

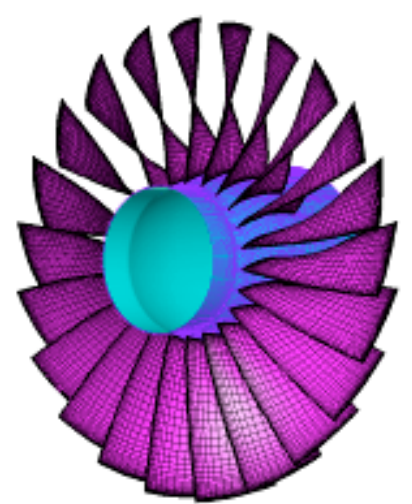

Figure 5. 3-D grid for the fan.

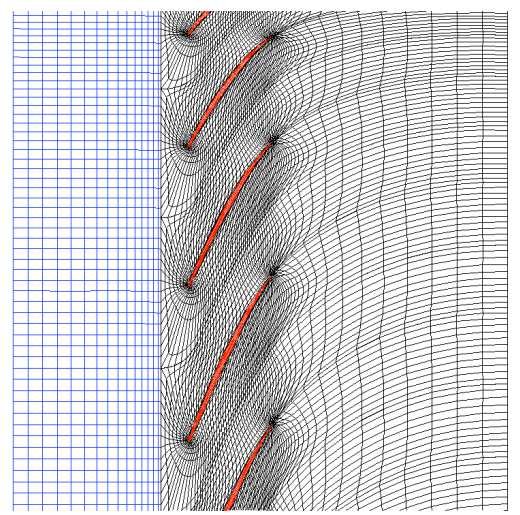

Figure 6. Blade-to-blade view of the fan grid near the tip.

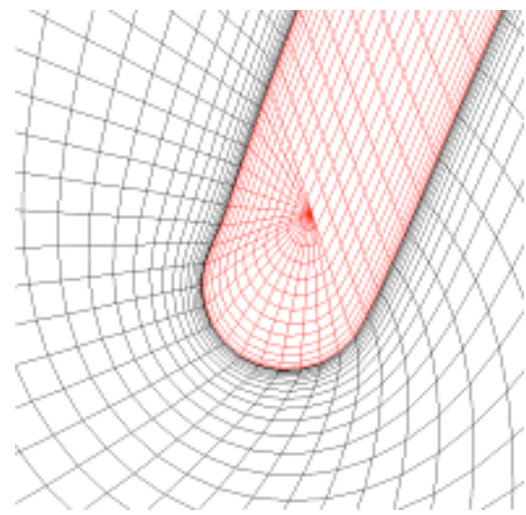

Figure 7. Tip clearance grid.

\begin{tabular}{|l|c|r|r|}
\hline Region & Type & Size $(\mathbf{x}, \boldsymbol{\theta}, \mathbf{r})$ & Total points \\
\hline upstream & $\mathrm{H}$ & $45 \times 30 \times 95$ & 128,250 \\
\hline rotor & $\mathrm{C}$ & $257 \times 46 \times 95$ & $1,123,090$ \\
\hline rotor tip & $\mathrm{O}$ & $201 \times 15 \times 15$ & 45,225 \\
\hline Total & & & $1,296,565$ \\
\hline
\end{tabular}

Table 2. Grid sizes for the fan rotor.

\section{Computational Details}

Coupled inlet/fan calculations were run using AVCS for the axisymmetric inlet and SWIFT for the 3-D fan. The codes were coupled at the interface between inlet and fan grids using the mixing plane boundary condition implemented in the SMPI code. SYNCEX, SMPI, and three copies of AVCS (for the three inlet grid blocks) were run on one PC and SWIFT was run simultaneously on a second PC. OpenMP was used to further parallelize each code on dual-core machines. 
The upstream boundary conditions were fixed at $M=1.7$. At the fan exit the static pressure was specified on the casing and the radial equilibrium equation was used to find the radial distribution of static pressure. The fan exit static pressure was varied between runs to set the fan mass flow rate. At the bypass exit the static pressure was set to the freestream value. At the design point the bypass duct was choked near the exit due to the specified blockage distribution so the corrected flow through the bypass duct was constant. However the total pressure at the entrance to the bypass duct varied with shock strength, so that the physical mass flow through the bypass duct varied slightly as the fan was throttled.

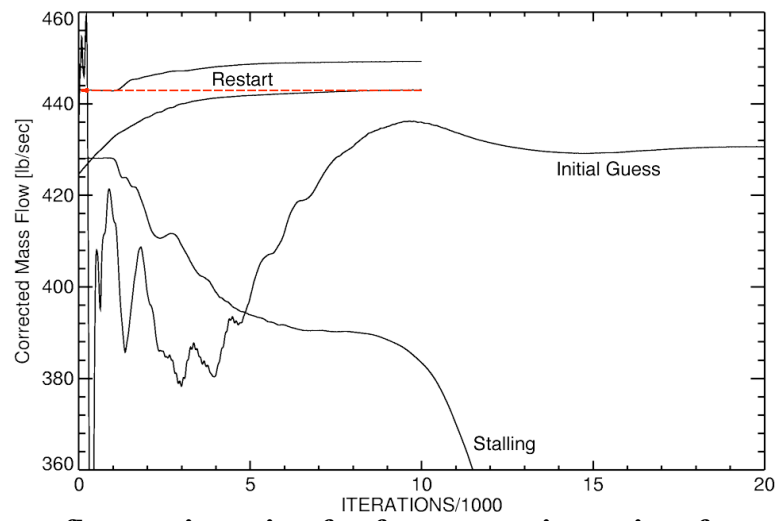

Figure 8. Core mass flow vs. iteration for four operating points from choke to stall.

All cases were run with a two-stage Runge-Kutta scheme at a Courant number of 2.5, using implicit residual smoothing to maintain stability. Most cases were run 10-20,000 iterations, which took 6-12 hours on 4 CPUs. Fan inlet mass flow and exit total pressure were monitored for convergence. Figure 8 shows that fan inlet mass flow converged in 10,000 iterations for most restart cases. When the fan exit pressure was set too high the inlet mass flow would drop continuously and the fan was considered to be stalled.

\section{Design Point Performance}

The third objective of the present work was to determine the performance of the inlet and fan at the design point. This was done by analyzing the inlet and fan separately and also as a coupled system. The results were compared to determine the effect that each component had on the other. The peak efficiency point of the coupled system was chosen as the design point

\section{A. Inlet Performance}

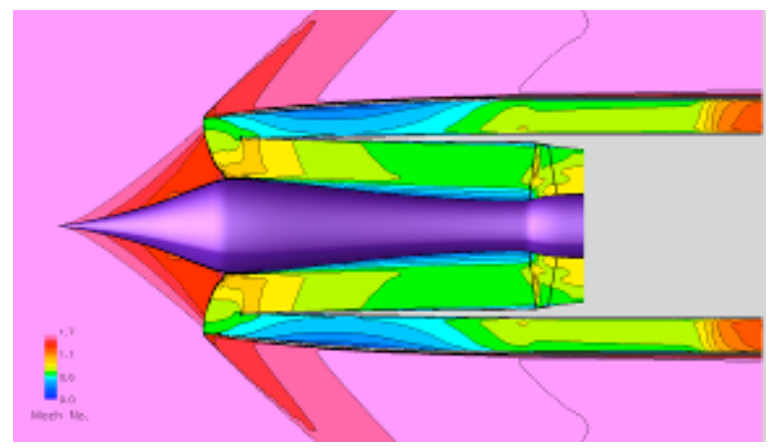

Maximum fan flow

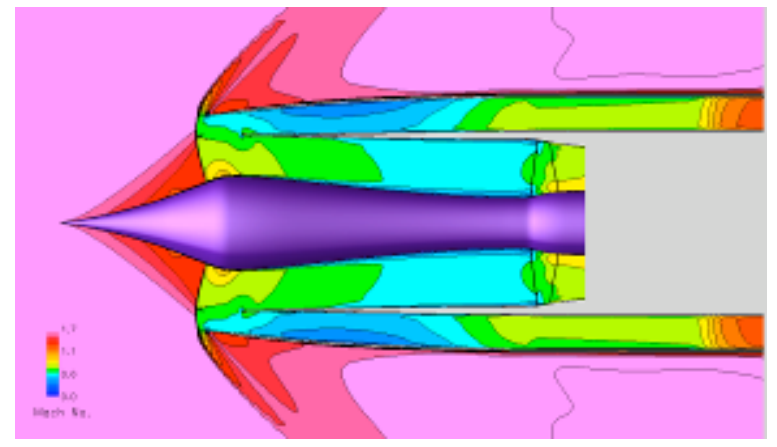

Near stall

Figure 9. Axisymmetric average Mach contours in the inlet and fan.

Coupled inlet/fan calculations were made for $M=1.7$ by varying the fan exit pressure over 12 operating points on the fan speed line. Figure 9 shows absolute Mach number contours for the inlet and fan at the extremes of the speed line. The 3-D fan solution has been averaged circumferentially, and the average solutions are continuous across the mixing plane interface. At maximum fan flow (left) the external spillage shock is minimized, the normal shock is pulled into the inlet, and a very thick boundary layer enters the fan at the hub. When the fan is throttled near 
stall (right) the inlet spills the excess flow, the normal shock is pushed ahead onto the spike, and the fan sees a somewhat thinner hub boundary layer. At cruise the fan would operate at some peak efficiency point between these extremes.
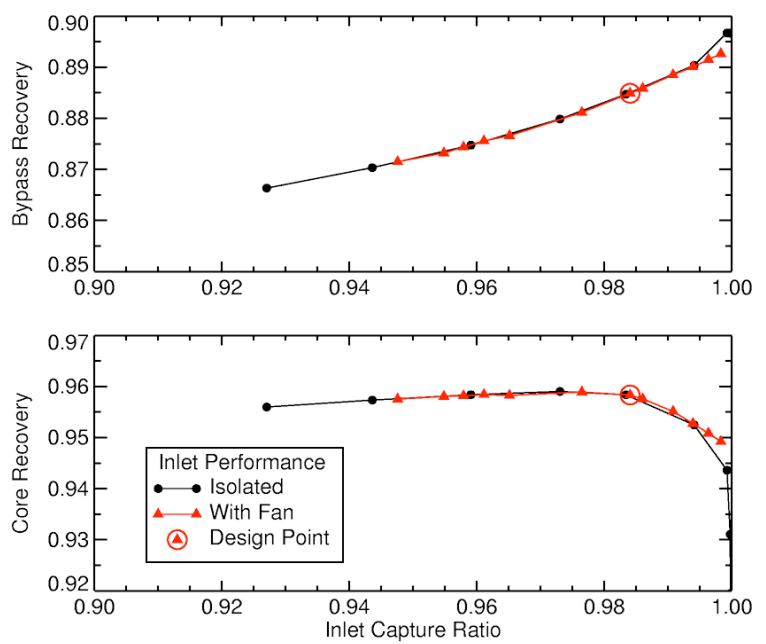

Figure 10. Core recovery (bottom) and bypass recovery (top) at $M=1.7$.

The bottom of Figure 10 shows a plot of predicted inlet core recovery versus inlet capture ratio, which is sometimes called a cane curve. Calculations for the isolated inlet (black) agree very closely with the coupled inlet/fan calculations (red) except at high flows, where the fan chokes before the inlet. The design point (circled) is at a capture ratio of 0.985 , i.e., 1.5 percent spillage, where the core recovery is nearly 0.96 . For comparison, at $M=1.7$ the recovery of the pitot inlet on the F-16 fighter is roughly 0.85 , the pressure ratio across a normal shock. Thirty-eight to 40 percent of the captured flow goes through the bypass duct, and the top of Figure 10 shows that the bypass recovery varies from 0.87 to 0.89 .
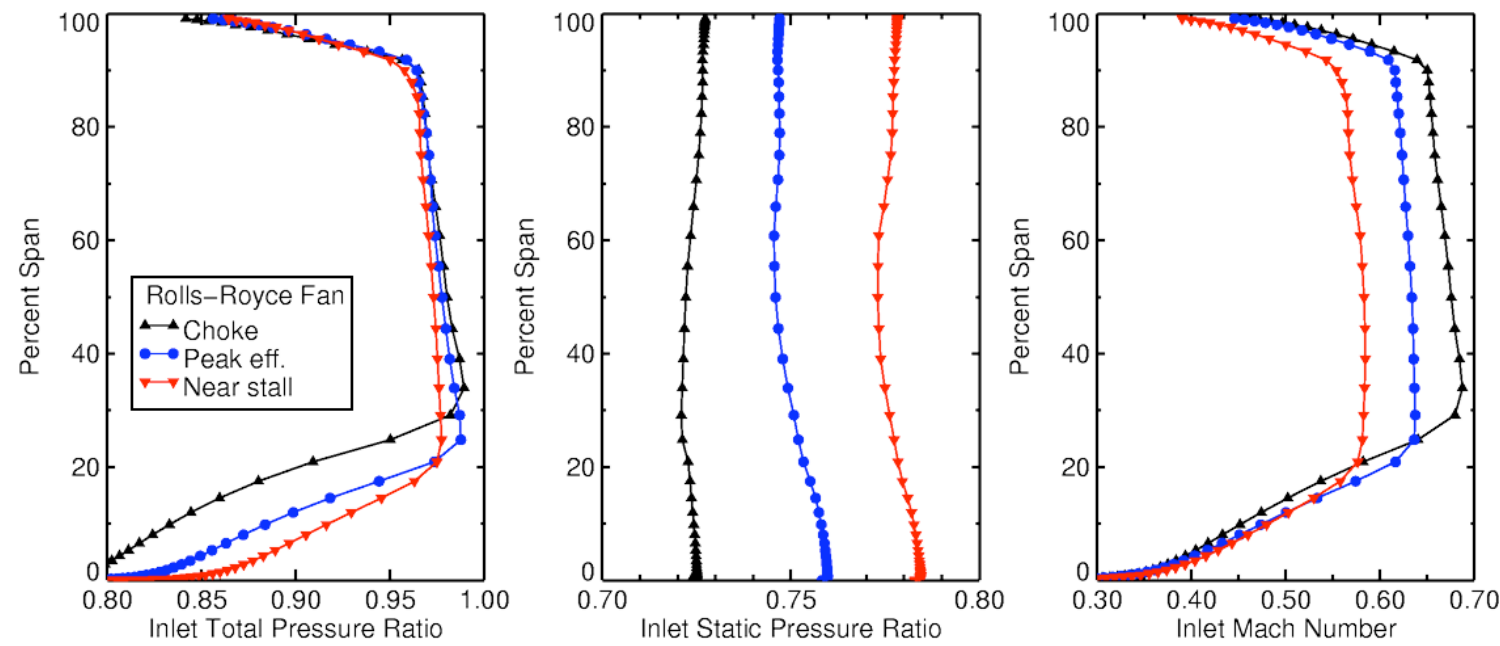

Figure 11. Comparison of AIP profiles at three fan operating points. Total pressure ratio (left), static pressure ratio (center), and Mach number (right).

In this inlet the long subsonic diffuser develops a thick hub boundary layer that grows from 20 percent span near stall to over 30 percent span at choke, as seen in total pressure profiles in Figure 11 (left). Most fans have a spinner that develops a thin hub boundary, so this hub radial distortion is an unusual phenomenon that could affect fan operability. Outside the boundary layer the total pressure recovery varies with shock losses by 1-2 points. Static pressure profiles (Fig. 11, center) are nearly linear for the coupled solutions, showing that it is reasonable to use a constant pressure exit boundary condition to model an isolated inlet. The average fan face Mach number (Fig. 11, right) varies from about 0.67 at choke to 0.56 near stall, consistent with a design Mach number of 0.65 . 


\section{B. Fan Performance}
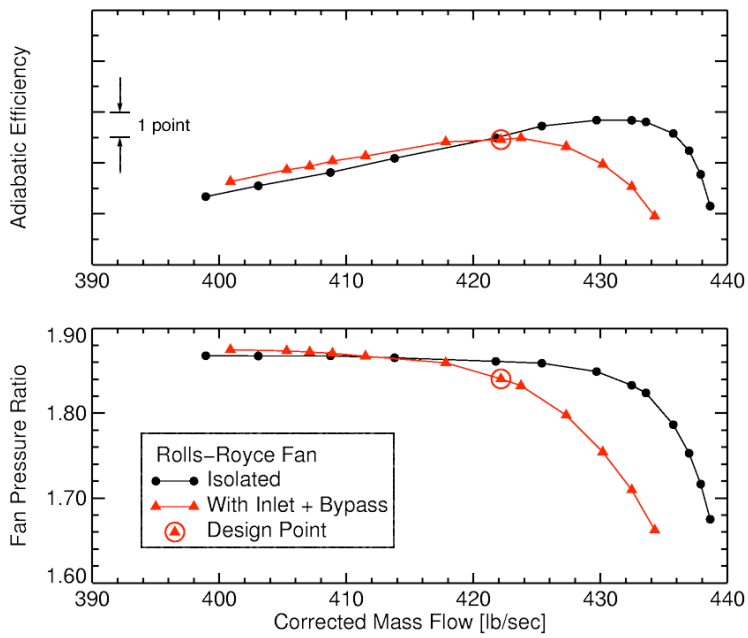

Figure 12. Comparison of fan performance characteristics with clean inflow (black) and with the inlet (red). Total pressure ratio (bottom) and adiabatic efficiency (top).

Two fan maps at 100 percent rotor speed are shown in Figure 12, one computed with clean inflow (black), and the other coupled to the inlet (red). When the inlet is included the maximum corrected flow decreases by about 1.1 percent. There is also a slight increase in the predicted stall flow, although it is probably insignificant due to uncertainties in predicting stall. The design point (circled) corresponds to the design point on inlet recovery curves shown in Figure 10. At the design point the fan operates near its peak pressure ratio (bottom) and peak efficiency (top), however, the addition of the inlet reduces the peak efficiency by 0.8 points and reduces the corrected mass flow at the peak efficiency point by $10 \mathrm{lb} / \mathrm{sec}$.
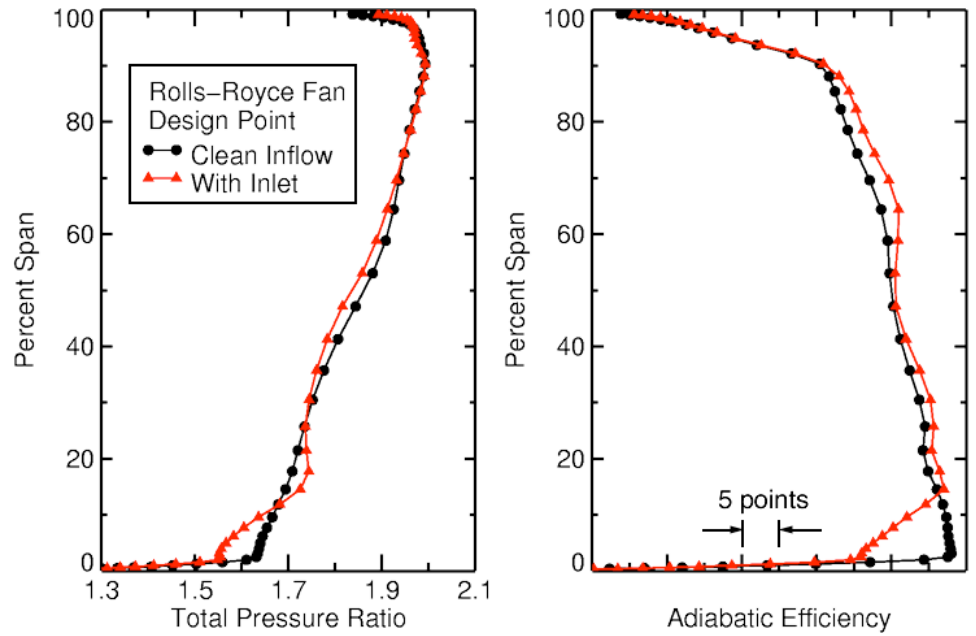

Figure 13. Comparison of fan exit profiles at the peak efficiency point with clean inflow (black) and with the inlet (red). Total pressure ratio (left) and adiabatic efficiency (right).

To show the effects of inlet hub radial distortion on the fan, Figure 13 compares fan exit profiles for the isolated fan (black) and the inlet/fan system (red) at the design point, where the inlet/fan system is at peak efficiency and the efficiency for the isolated fan is (coincidentally) the same. The total pressure ratio profile (left) for the isolated fan increases almost linearly from hub to tip, but the profile for the inlet/fan system shows that hub radial distortion from the inlet is not eliminated by the fan and persists to the fan exit. The hub distortion is particularly evident in the adiabatic efficiency distribution (right). This distortion could then be a concern for the engine booster stages, which are about one-third as high as the fan. 


\section{Flight Profile Performance and Operability}

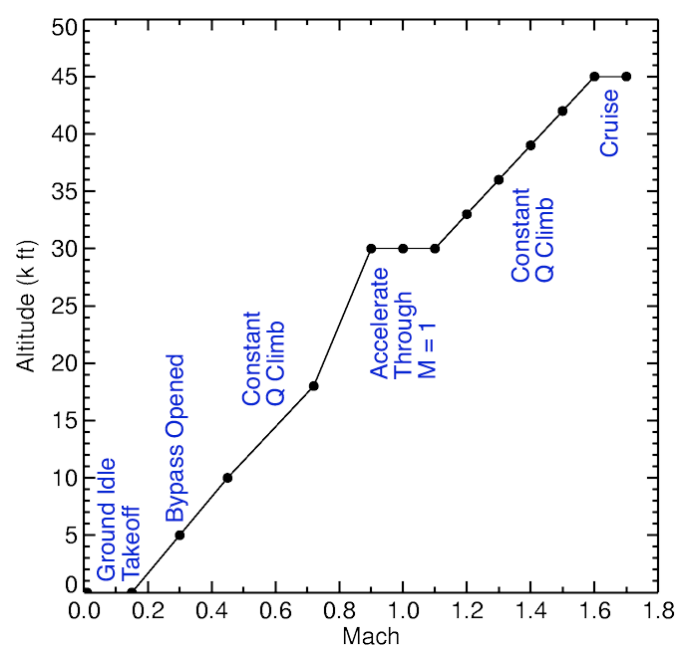

Figure 14. Nominal flight profile for the Quiet Supersonic Jet.

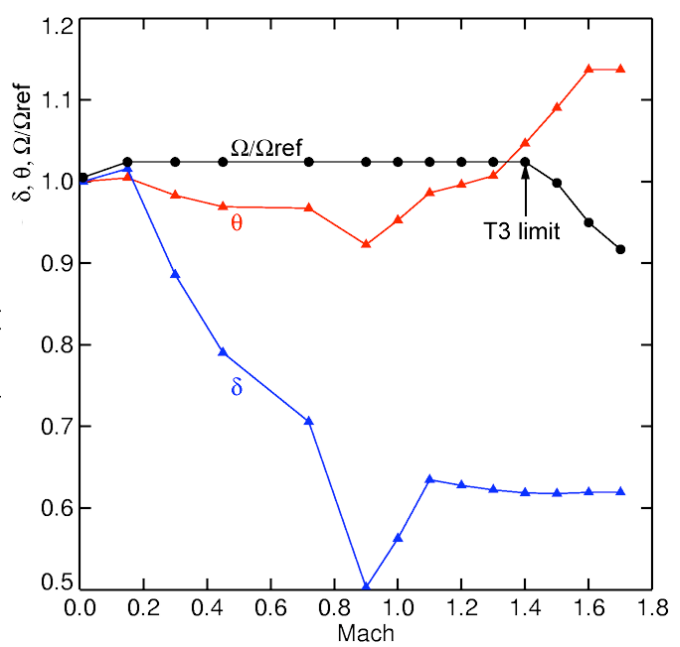

Figure 15. Variation of total temperature ratio $\theta$, total pressure ratio $\delta$, and rotor speed $\Omega$ along the flight profile.

The final objective of this work was to assess the operability of the inlet / fan system over the nominal flight profile of the aircraft. The flight profile supplied by Gulfstream is shown in Figure 14. It starts with the system at ground idle and proceeds through takeoff to climb at constant dynamic pressure. At low Mach numbers the pressure gradient across the bypass duct is low, and the fan would actually draw flow backwards from the nozzle through the bypass duct. To avoid hot gas ingestion the bypass duct would be blocked at low Mach numbers, perhaps with spring-loaded doors. At $M=0.3$ the pressure drop across the bypass is sufficient to ensure forward flow and the bypass would be reopened. At $M=0.9$ and $30,000 \mathrm{ft}$. altitude the flight profile levels off and the aircraft accelerates through Mach 1. At $M=1.10$ the aircraft resumes its acceleration and climb to its cruising condition of $M=1.6$ at $45,000 \mathrm{ft}$. The inlet is assumed to operate at $M=1.7$ over the wing.

As the aircraft climbs the static pressure and temperature of the standard atmosphere decrease with altitude, but as the aircraft accelerates the total pressure and temperature of the freestream flow increase. Figure 15 shows how the total pressure and temperature ratios $\delta=P_{0, \infty} / P_{0, S L S}$ and $\theta=T_{0, \infty} / T_{0, S L S}$ vary with Mach number along the flight profile. Here SLS refers to sea level standard conditions. Figure 15 also shows the normalized rotational speed of the fan, $\Omega$, which is constant for $M<1.4$. At $M=1.4$ the total temperature ratio $\theta>1$ and the rotational speed must be reduced to limit the compressor exit temperature T3. The schedule for $\Omega$ was supplied by Rolls-Royce.

Coupled CFD simulations of the inlet and fan were run for each point on the flight path shown in Figure 14. The boundary conditions were set as follows:

Upstream

- Subsonic: $P_{0 \infty}, T_{0 \infty}$ specified, $v_{x}$ extrapolated from interior

- Supersonic: all flow variables specified

Downstream and bypass exit

- Bypass closed for $M<0.3$

- Subsonic: Ps specified based on $M_{\infty}$

- Supersonic: all flow variables extrapolated

Freestream

- Characteristic variables perturbed about freestream

- Reynolds number varied with altitude: $\operatorname{Re}=f\left(P_{0 \infty}, T_{0 \infty}\right)$

Fan

- $\Omega$ specified as shown in Figure 15, corrected speed varied with $\theta: N c=\Omega \sqrt{\theta}$.

- Ps linear with $N_{C}$, mass flow matched to cycle deck flow rate at several operating points 


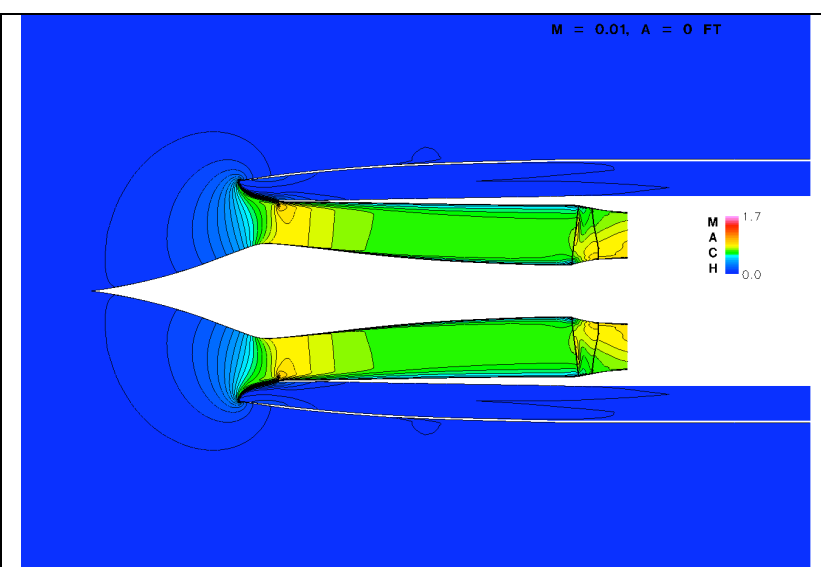

a. $\mathbf{M}=0.01$, altitude $=0$. Bypass exit is closed, flow is entirely subsonic.

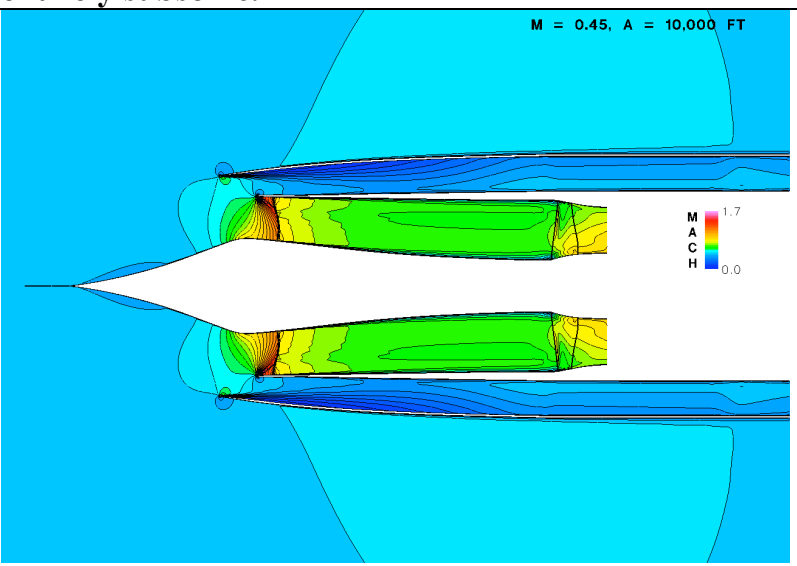

b. $\mathrm{M}=\mathbf{0 . 4 5}$, altitude $=10,000 \mathrm{ft}$. Bypass exit is open, diffuser is choked.

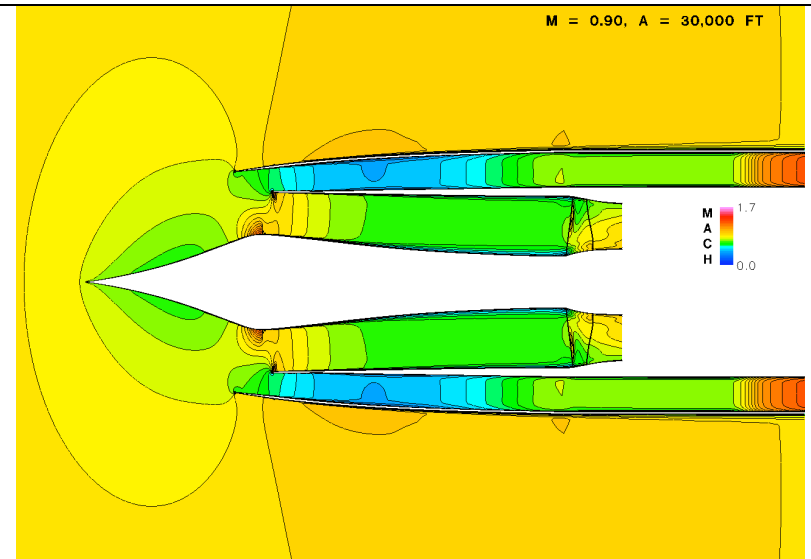

c. $\mathrm{M}=0.90$, altitude $=30,000 \mathrm{ft}$. Bypass is choked, weak shocks on inlet shoulder and bypass lip.

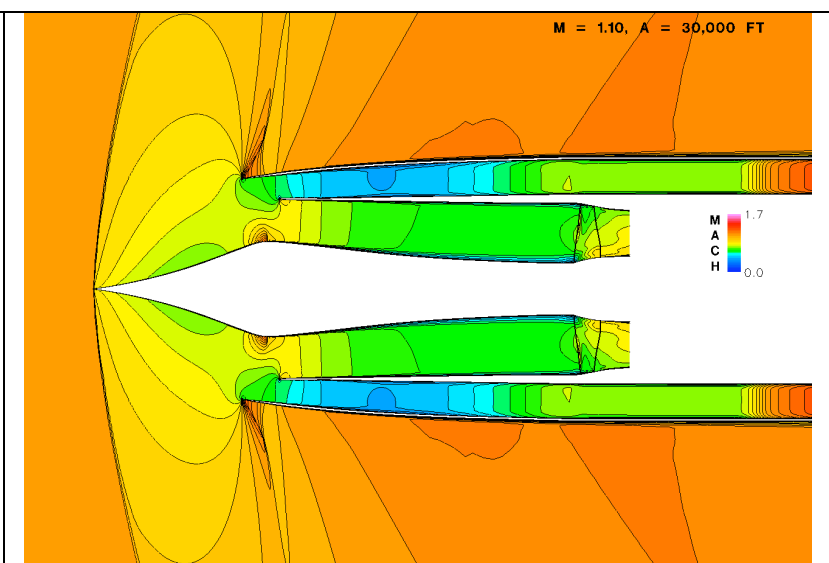

d. $M=1.10$, altitude $=30,000 \mathrm{ft}$. Weak shocks on spike and cowl lip.

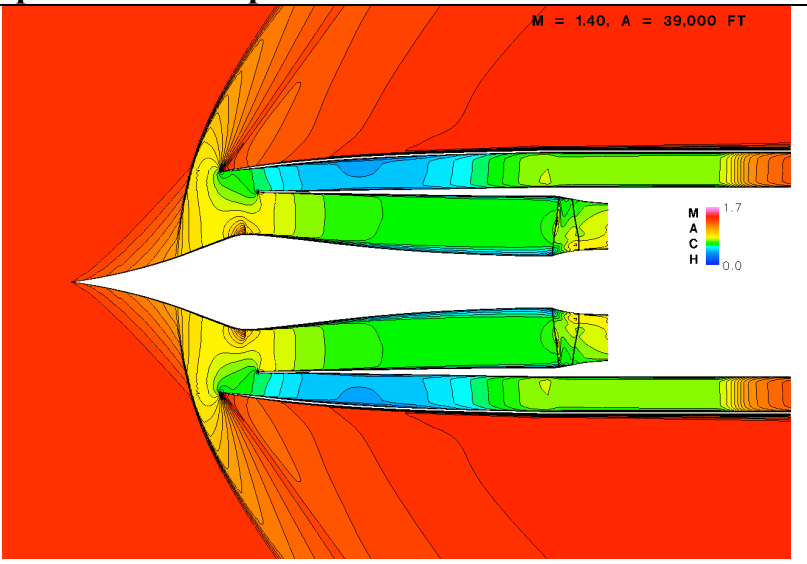

e. $\mathrm{M}=1.40$, altitude $=39,000 \mathrm{ft}$. Shock moves aftward on spike.

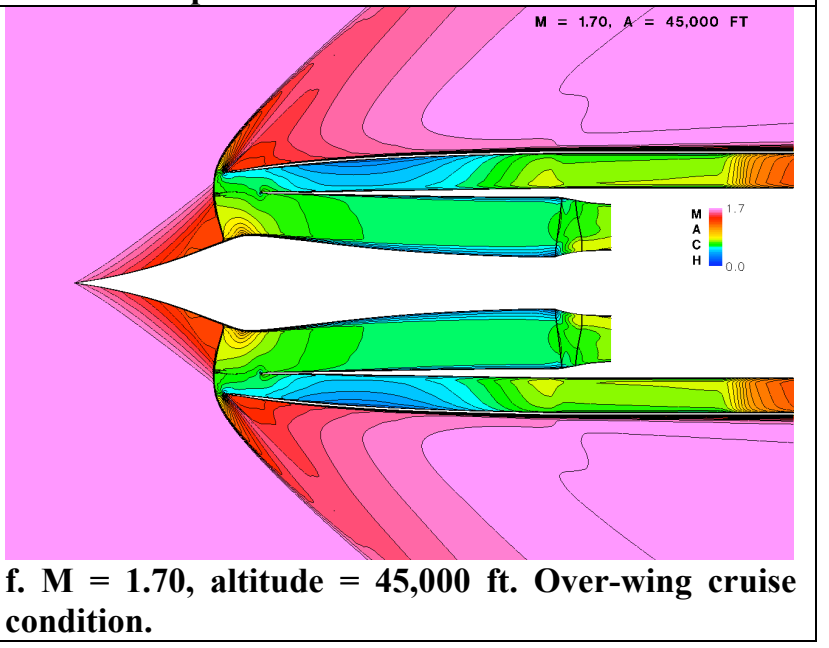

Figure 16. Mach number contours at selected points along the flight profile.

Mach number contours for the inlet and fan at several points along the flight profile are shown in Figure 16. The 3-D solution in the fan has been averaged tangentially and the absolute Mach number in the fan is shown.

At ground idle, $M=0.01$ and altitude $=0$ (Figure 16a), the bypass exit is closed and the flow recirculates in the bypass duct. This creates a large incidence angle and a separation bubble on the inside surfaces of the cowl and the bypass splitter lip. The resulting tip boundary layer at the fan face has a height of 30 percent span, although the diffuser hub boundary layer is relatively small with a height of 15 percent span. 
The bypass duct would be opened at $M \approx 0.30$. As the Mach number increases above $M=0.30$ the flow through the bypass duct increases, the lip separation disappears, and the fan tip boundary layer decreases to nine percent span. Thus from $M=0.01$ to $M=0.40$ the boundary layer profiles at the AIP change dramatically and the fan operates close to its stall line (shown later), making it very difficult to analyze the fan as an isolated component in this portion of the flight profile.

At $M=0.45$ and altitude $=10,000 \mathrm{ft}$. (Figure 16b) the bypass is open and the bypass duct is flowing well. The fan flow is also high and the diffuser is choked. At the AIP the hub boundary layer height is about 15 percent span and the tip boundary layer height is about nine percent span. The hub boundary layer grows continuously through the rest of the flight profile but the tip boundary layer remains the same.

For $M>0.7$ the bypass is choked and the bypass flow exits supersonically, as shown in Figure 16c-f. At $M=0.90$ and altitude $=30,000 \mathrm{ft}$. (Figure 16c) small supersonic bubbles form on the core inlet shoulder and lip.

At $M=1.10$ and altitude $=30,000 \mathrm{ft}$. (Figure 16d) the first shocks appear at the tip of the spike and cowl lip. At $M=1.40$ and altitude $=39,000 \mathrm{ft}$. (Figure 16e) the bow shock has moved about half way along the spike. As the shock losses increase the actual mass flow through the inlet decreases, especially in the bypass duct.

Over the wing at cruise, $M=1.70$ and altitude $=45,000 \mathrm{ft}$. (Figure 16e), the bow shock sits on the spike just ahead of the shoulder. The hub boundary layer is attached but grows through the diffuser to about 25 percent span at the AIP, as seen in Figure 11.

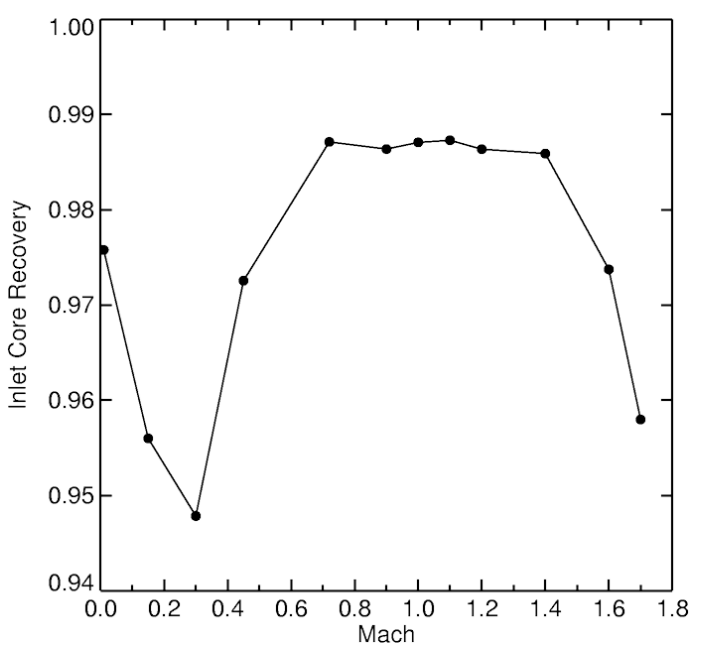

Figure 17. Core inlet recovery vs. Mach number along the flight path.
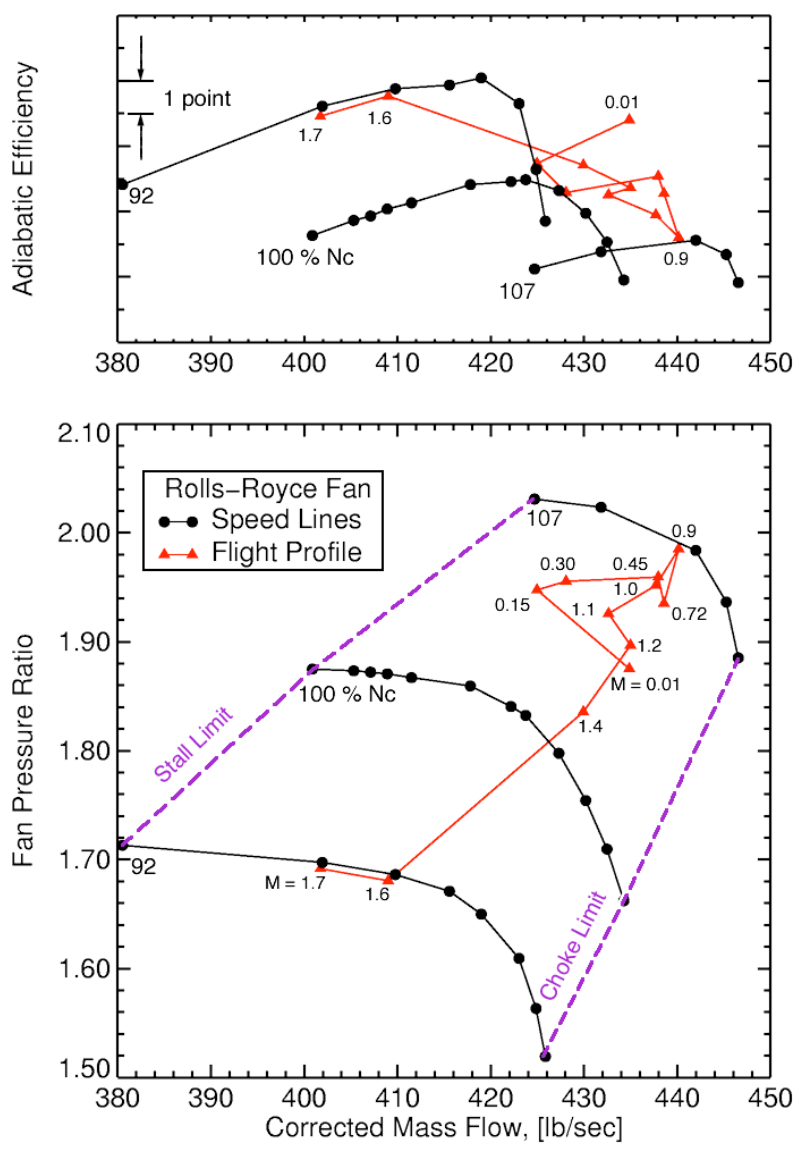

Figure 18. Fan speed lines (black) and performance maps along the flight path (red.) Top - adiabatic efficiency. Bottom - fan pressure ratio.

Core inlet recovery is plotted against Mach number along the flight path in Figure 17. The recovery is reduced for $0.1<M<0.4$ because of separation at the bypass lip, and further investigation of the lip design is warranted. The recovery is excellent, about 0.988 , for $0.4<M<1.4$. Shock losses increase for $M>1.4$ and the recovery decreases accordingly. 
The computed fan map is shown in Figure 18. Fan total pressure ratio is plotted against corrected flow, $\dot{m}_{c}=\dot{m} \sqrt{\theta} / \delta$, at the bottom. Corrected flow exactly accounts for uniform changes in freestream total conditions and partially accounts for changes in inlet recovery due to inlet radial distortion.

Three lines of constant corrected speed are shown (black circles). The 100 percent speed line is duplicated from the coupled solutions shown in Figure 12, and the 92 and 107 percent speed lines were computed for an isolated fan with design point distortion. The choke and stall lines are indicated with dashed purple lines and the fan pressure ratio along the flight profile is shown with red up-triangles. The flight profile starts at $M=0.01$ with $N_{C} \approx 103 \%$ near the upper right corner of the plot. In general the fan corrected flow and pressure ratio increase along an operating line until $M=0.9$ with $N_{C} \approx 107 \%$, then decrease until $M=1.7$ with $N_{C} \approx 92 \%$. Two points at $M=0.15$ and $M=0.30$ operate close to the stall line due to separation at the splitter lip which produces a thick casing boundary layer at the AIP. The fan adiabatic efficiency shown at the top of Figure 18 tends to follow the peak efficiency point of each speed line, as desired.

\section{Summary and Conclusions}

Two coupled CFD codes were used to model the inlet and fan of a Quiet Supersonic Jet being studied at Gulfstream Aerospace Corporation. The isentropic external compression inlet was analyzed using an axisymmetric RANS code called AVCS. A novel bypass duct that channels flow subsonically around the engine gearbox and diverts low total pressure flow away from the fan tip was modeled using a blockage model in AVCS. The RollsRoyce fan was analyzed using a 3-D RANS code called SWIFT. The two codes were coupled at the AIP using a data interchange code called SYNCEX and a mixing plane boundary condition code called SMPI.

The codes were used to determine the performance of the inlet /fan system at the design inlet Mach number of 1.7 and to investigate the operability of the system over the flight profile. At the design point the core inlet had a recovery of 96 percent, and the fan operated near its peak efficiency and pressure ratio points. However, a large hub radial distortion generated in the inlet was not eliminated by the fan and could pose a challenge for subsequent booster stages. Stable operation was found at all points along the flight profile. Reduced stall margin was seen at low altitude and Mach number where the flow separates on the interior lip of the bypass duct. A redesign of the lip is now under consideration.

The inlet and fan were analyzed separately and also as a coupled system. The results were compared to determine the effect that each component had on the other. It was found that the fan chokes before the inlet and modifies the inlet performance predictions at the highest flow rates. Although the fan can be analyzed separately at most operating points using nominal total pressure profiles from the inlet solutions, it is difficult to specify consistent profiles at low altitude and Mach number conditions where the inlet distortion changes dramatically with flight conditions and the fan operates near stall.

There were a few disadvantages to the coupled analyses including increased complexity in grid generation and boundary condition specification, and longer solution times. The advantages of the coupled analysis include elimination of modeling at the AIP, the ability to track inlet distortion effects all the way through the fan, and the ability to generate consistent solutions at all flight conditions.

\section{References}

1. Goldsmith, E. L., and Seddon, J. ed., Practical Intake Aerodynamic Design, AIAA, Inc. Washington, DC, 1993, pp. 14.

2. SAE S-16 Committee, ARP 1420, Revision B, "Gas Turbine Inlet Flow Distortion Guidelines," Society of Automotive Engineers, Feb. 2002.

3. Hsiao, E., Naimi, M., Lewis, J. P., Dalbey, K., Gong, Y., and Tan, C., "Actuator Duct Model of Turbomachinery for Powered-Nacelle Navier-Stokes Calculations," J. Propulsion and Power, Vol. 17, No. 4, Jul.-Aug. 2001.

4. Davis, M. W., Hale, A. H., Vining, C., and Cousins, W. T., "Application of Numerical Analysis Tools for AirframePropulsion Integrated Test and Evaluation,” ASME Paper GT2008-50194, June 2008.

5. Chima, R. V., Arend, D. J., Castner, R. S., Slater, J. W., and Truax, P. P., "CFD Models of a Serpentine Inlet, Fan, and Nozzle," AIAA Paper 2010-33, Jan. 2010.

6. Steenken, W. G., "Integrated Inlet-Engine Compatibility by Design," AIAA Paper 2009-5460, Aug. 2009.

7. Wilson, J. R., Quiet Spike Softening the Sonic Boom, Aerospace America, Oct. 2007, pp. 38- 42.

8. Conners, T. R., and Howe, D. C., "Supersonic Inlet Shaping for Dramatic Reductions in Drag and Sonic Boom Strength," AIAA Paper 2006-30, Jan. 2006.

9. Conners, T. R., Merret, J. M., Howe, D. C., Tacina, K. M., and Hirt, S. M., "Wind Tunnel Testing of an Axisymmetric Relaxed External Compression Inlet at Mach 1.97 Design Speed,” AIAA Paper 2007-5066, July, 2007. 
10. Hirt, S. M., Tacina, K. M., Conners, T. R., Merret, J. M., and Howe, D. C., "CFD Results for an Axisymmetric Isentropic Relaxed Compression Inlet," AIAA Paper 2008-0092, Nov. 2008. Also NASA TM-2008-215416.

11. Rybalko, M., Loth, E., Chima, R. V., Hirt, S. M., and DeBonis, J. R., "Micro Ramps for External Compression Low-Boom Inlets," AIAA Paper 2009-4206, June 2009.

12. Chima, R. V., "Viscous Three-Dimensional Calculations of Transonic Fan Performance," in CFD Techniques for Propulsion Applications," AGARD Conference Proceedings No. CP-510, AGARD, Neuilly-Sur-Seine, France, Feb. 1992, pp. 21-1 to 21-19. Also NASA TM-103800.

13. Chima, R. V. and Liou, M.-S., "Comparison of the AUSM ${ }^{+}$and H-CUSP Schemes for Turbomachinery Applications," AIAA Paper AIAA-2003-4120. Also NASA TM-2003-212457.

14. Wilcox, D. C., Turbulence Modeling for CFD, Third Edition, DCW Industries, Inc., La Canada, CA, 2006.

15. Chima, R. V., "A k- $\omega$ Turbulence Model for Quasi-Three-Dimensional Turbomachinery Flows," AIAA Paper 96-0248. Also NASA TM-107051.

16. Tweedt, D. L. and Chima, R. V., "Rapid Numerical Simulation of Viscous Axisymmetric Flows," AIAA Paper 96-0449, Jan. 1996. Also NASA TM-107103.

17. Giles, M. B., "Nonreflecting Boundary Conditions for Euler Equation Calculations," AIAA Journal, Vol. 28, No. 12, Dec. 1990. 


\begin{tabular}{|c|c|c|}
\hline \multicolumn{2}{|c|}{ REPORT DOCUMENTATION PAGE } & $\begin{array}{l}\text { Form Approved } \\
\text { OMB No. 0704-0188 }\end{array}$ \\
\hline \multicolumn{3}{|c|}{ 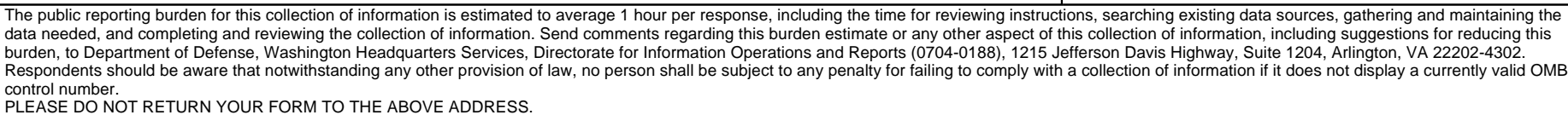 } \\
\hline $\begin{array}{l}\text { 1. REPORT DATE (DD-MM-YYYY) } \\
01-05-2010\end{array}$ & $\begin{array}{l}\text { 2. REPORT TYPE } \\
\text { Technical Memorandum }\end{array}$ & 3. DATES COVERED (From - To) \\
\hline \multirow{3}{*}{\multicolumn{2}{|c|}{$\begin{array}{l}\text { 4. TITLE AND SUBTITLE } \\
\text { Coupled Analysis of an Inlet and Fan for a Quiet Supersonic Jet }\end{array}$}} & 5a. CONTRACT NUMBER \\
\hline & & 5b. GRANT NUMBER \\
\hline & & 5c. PROGRAM ELEMENT NUMBER \\
\hline \multirow{3}{*}{\multicolumn{2}{|c|}{$\begin{array}{l}\text { 6. AUTHOR(S) } \\
\text { Chima, Rodrick, V.; Conners, Timothy, R.; Wayman, Thomas, R. }\end{array}$}} & 5d. PROJECT NUMBER \\
\hline & & 5e. TASK NUMBER \\
\hline & & $\begin{array}{l}\text { 5f. WORK UNIT NUMBER } \\
\text { WBS 984754.02.07.03.13.02 }\end{array}$ \\
\hline \multicolumn{2}{|c|}{$\begin{array}{l}\text { 7. PERFORMING ORGANIZATION NAME(S) AND ADDRESS(ES) } \\
\text { National Aeronautics and Space Administration } \\
\text { John H. Glenn Research Center at Lewis Field } \\
\text { Cleveland, Ohio 44135-3191 }\end{array}$} & $\begin{array}{l}\text { 8. PERFORMING ORGANIZATION } \\
\text { REPORT NUMBER } \\
\text { E-17286 }\end{array}$ \\
\hline \multirow{2}{*}{\multicolumn{2}{|c|}{$\begin{array}{l}\text { 9. SPONSORING/MONITORING AGENCY NAME(S) AND ADDRESS(ES) } \\
\text { National Aeronautics and Space Administration } \\
\text { Washington, DC 20546-0001 }\end{array}$}} & $\begin{array}{l}\text { 10. SPONSORING/MONITOR'S } \\
\text { ACRONYM(S) } \\
\text { NASA }\end{array}$ \\
\hline & & $\begin{array}{l}\text { 11. SPONSORING/MONITORING } \\
\text { REPORT NUMBER } \\
\text { NASA/TM-2010-216350 }\end{array}$ \\
\hline \multicolumn{3}{|c|}{$\begin{array}{l}\text { 12. DISTRIBUTIONIAVAILABILITY STATEMENT } \\
\text { Unclassified-Unlimited } \\
\text { Subject Category: } 07 \\
\text { Available electronically at http://gltrs.grc.nasa.gov } \\
\text { This publication is available from the NASA Center for AeroSpace Information, 443-757-5802 }\end{array}$} \\
\hline
\end{tabular}

\section{SUPPLEMENTARY NOTES}

\section{ABSTRACT}

A computational analysis of a Gulfstream isentropic external compression supersonic inlet coupled to a Rolls-Royce fan has been completed. The inlet was designed for a small, low sonic boom supersonic vehicle with a design cruise condition of $\mathrm{M}=1.6 \mathrm{at} 45,000 \mathrm{ft}$. The inlet design included an annular bypass duct that routed flow subsonically around an engine-mounted gearbox and diverted flow with high shock losses away from the fan tip. Two Reynolds-averaged Navier-Stokes codes were used for the analysis: an axisymmetric code called AVCS for the inlet and a three dimensional (3-D) code called SWIFT for the fan. The codes were coupled at a mixing plane boundary using a separate code for data exchange. The codes were used to determine the performance of the inlet/fan system at the design point and to predict the performance and operability of the system over the flight profile. At the design point the core inlet had a recovery of 96 percent, and the fan operated near its peak efficiency and pressure ratio. A large hub radial distortion generated in the inlet was not eliminated by the fan and could pose a challenge for subsequent booster stages. The system operated stably at all points along the flight profile. Reduced stall margin was seen at low altitude and Mach number where flow separated on the interior lips of the cowl and bypass ducts. The coupled analysis gave consistent solutions at all points on the flight profile that would be difficult or impossible to predict by analysis of isolated components.

\section{SUBJECT TERMS}

Computational fluid dynamics; CFD; Inlet; Fan; Nozzle

\begin{tabular}{|c|c|c|c|c|c|}
\hline \multicolumn{3}{|c|}{ 16. SECURITY CLASSIFICATION OF: } & \multirow{2}{*}{$\begin{array}{l}\text { 17. LIMITATION OF } \\
\text { ABSTRACT } \\
\text { UU }\end{array}$} & \multirow{2}{*}{$\begin{array}{l}\text { 18. NUMBER } \\
\text { OF } \\
\text { PAGES } \\
19\end{array}$} & \multirow{2}{*}{$\begin{array}{l}\text { 19a. NAME OF RESPONSIBLE PERSON } \\
\text { STI Help Desk (email:help@sti.nasa.gov) } \\
\text { 19b. TELEPHONE NUMBER (include area code) } \\
\text { 443-757-5802 }\end{array}$} \\
\hline $\begin{array}{l}\text { a. REPORT } \\
\text { U }\end{array}$ & $\begin{array}{l}\text { b. ABSTRACT } \\
\text { U }\end{array}$ & $\begin{array}{l}\text { c. THIS } \\
\text { PAGE } \\
\text { U }\end{array}$ & & & \\
\hline
\end{tabular}



